Brit. Heart f., 1969, 31, 770.

\title{
Electrocardiographic Changes Subsequent to Artificial Ventricular Depolarization
}

\author{
KANU CHATTERJEE, ALAN HARRIS, GEOFFREY DAVIES, AND \\ AUBREY LEATHAM
}

From the Cardiac Department, St. George's Hospital, London S.W.1

Massive $\mathrm{T}$ wave inversion and ST depression occur in the unpaced electrocardiogram subsequent to ventricular pacing, and persist for a varying length of time depending on the duration of pacing. That artificial depolarization of the ventricle causes changes in repolarization which persist after stopping pacing is of considerable theoretical and practical importance, and we describe the findings in 31 patients both with and without disease of the conduction tissue.

Received May 5, 1969.

\section{SubJeCts AND Methods}

Thirty-one patients were studied, 11 women, and 20 men, and their ages ranged from 42 to 84 years (mean 67 years): 30 were being paced from the endocardium by transvenous electrode wires, and one from the left ventricular epicardium by epicardial electrodes, all with external units at the time of investigation.

Twenty-six patients were paced for chronic atrioventricular (AV) conduction disease with Adams-Stokes attacks. Three were paced after acute myocardial infarcts with temporary disturbance of AV conduction, in order to prevent Adams-Stokes attacks. The

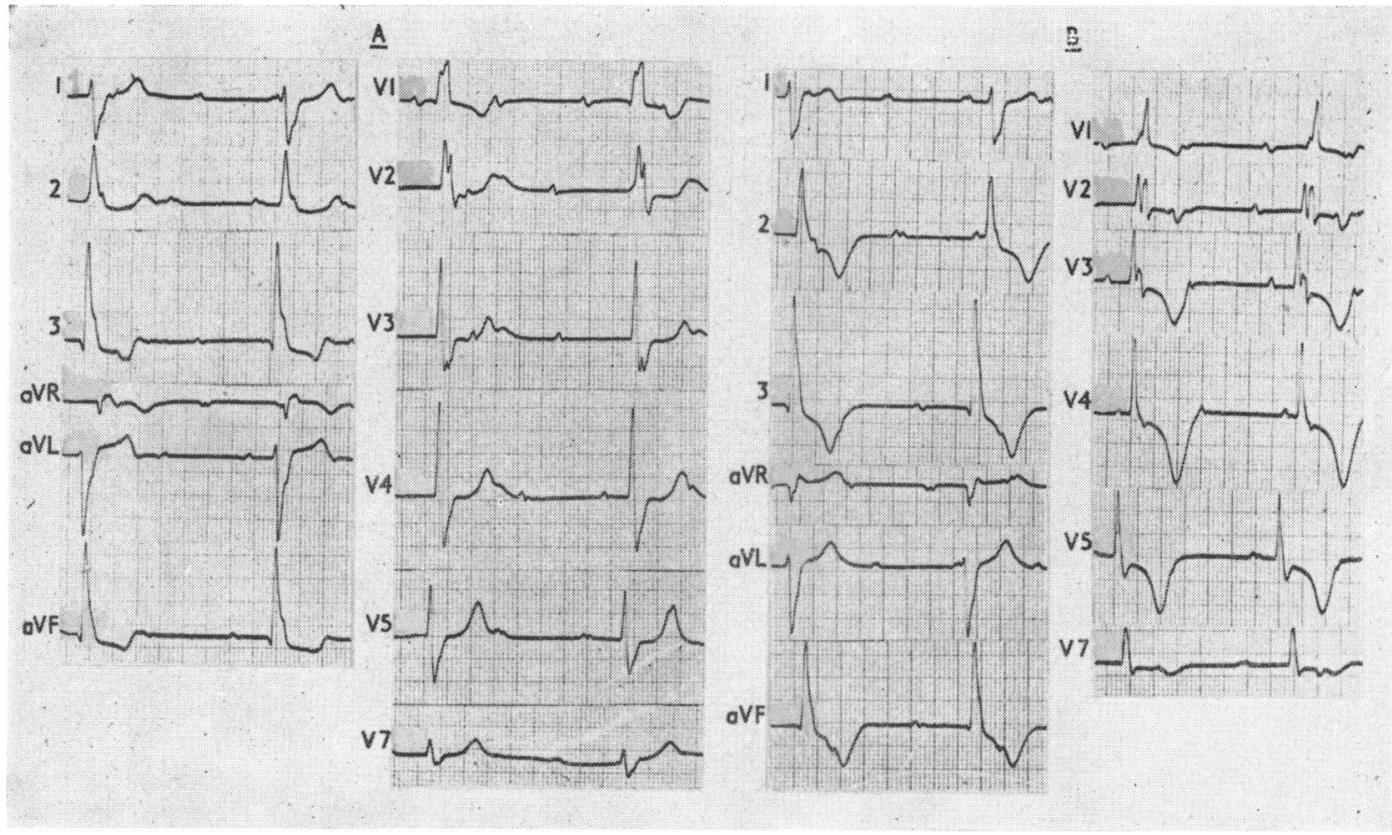

FIG. 1.-(A) Electrocardiogram showing complete heart block with right bundle-branch block pattern. (B) Unpaced electrocardiogram after 24 hours of right ventricular endocardial pacing shows conspicuous $T$ inversion in leads II, III, aVF, and V2-V5. 


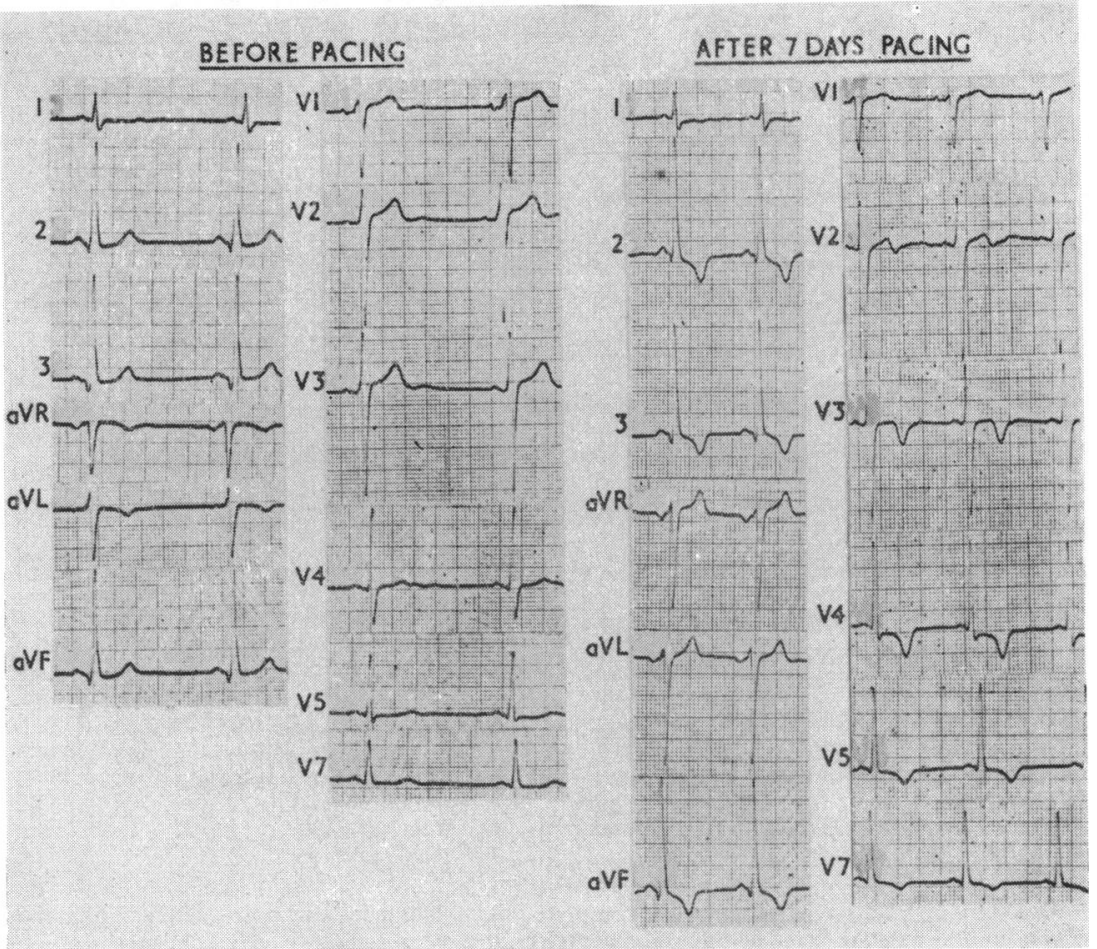

Frg. 2.-Electrocardiograms of a patient with intermittent complete heart block. Pre-paced electrocardiogram shows sinus rhythm with normal QRS complex. After 7 days of continuous ventricular pacing, an unpaced electrocardiogram shows conspicuous T inversion in II, III, aVF, and V3-V7, showing post-pacing T and ST changes in a patient with sinus rhythm.

remaining 2 patients were free of conduction tissue disease and were paced during the course of cardiac catheterization for the investigation of coronary artery disease.

The rhythm in the 26 patients paced for AdamsStokes attacks was complete heart block in 19, sinus with intermittent complete block in 5, and intermittent sinoatrial arrest in 2 . When the 3 patients with acute infarcts were investigated, normal sinus rhythm had been re-established for two weeks. The QRS duration was $0.12 \mathrm{sec}$. or more in 23 patients and of right bundlebranch block pattern in 17 and left in 6 .

A conventional 12-lead electrocardiogram was recorded in all patients lying in the supine position at approximately 30 degrees. The electrocardiograms at standard sensitivity and speed were recorded before and after varying periods of continuous ventricular pacing, which ranged from 5 minutes to 57 months. The postpaced electrocardiograms were recorded after the patients had been carefully weaned off the pacemaker and stable supraventricular or idioventricular rhythm re-established.

In both pre-paced and post-paced electrocardiograms the following parameters were compared: rhythm, atrial and ventricular rate, presence or absence and type of bundle-branch block, polarity and magnitude of QRS and $T$ waves and ST changes (expressed in Ashman units -1 Ashman unit $=4 \mu$ volt sec.) (Ashman and Byer, 1943).

\section{RESULTS}

After ventricular pacing, massive $T$ wave inversion and conspicuous ST depression were found in both limb and praecordial leads of unpaced electrocardiograms, without change in QRS complex, in all patients except 2 who had sinus rhythm and left bundle-branch block. These changes occurred in the post-paced electrocardiograms whether the rhythm was supraventricular or idioventricular (Fig. 1 and 2), and were independent of atrial rate and $Q R S$ duration.

The site of stimulation of the ventricle was found to influence the lead of the electrocardiogram which showed the most conspicuous changes. In 27 of the 29 patients who showed changes, the stimulating electrode had been placed in the apical region of the 

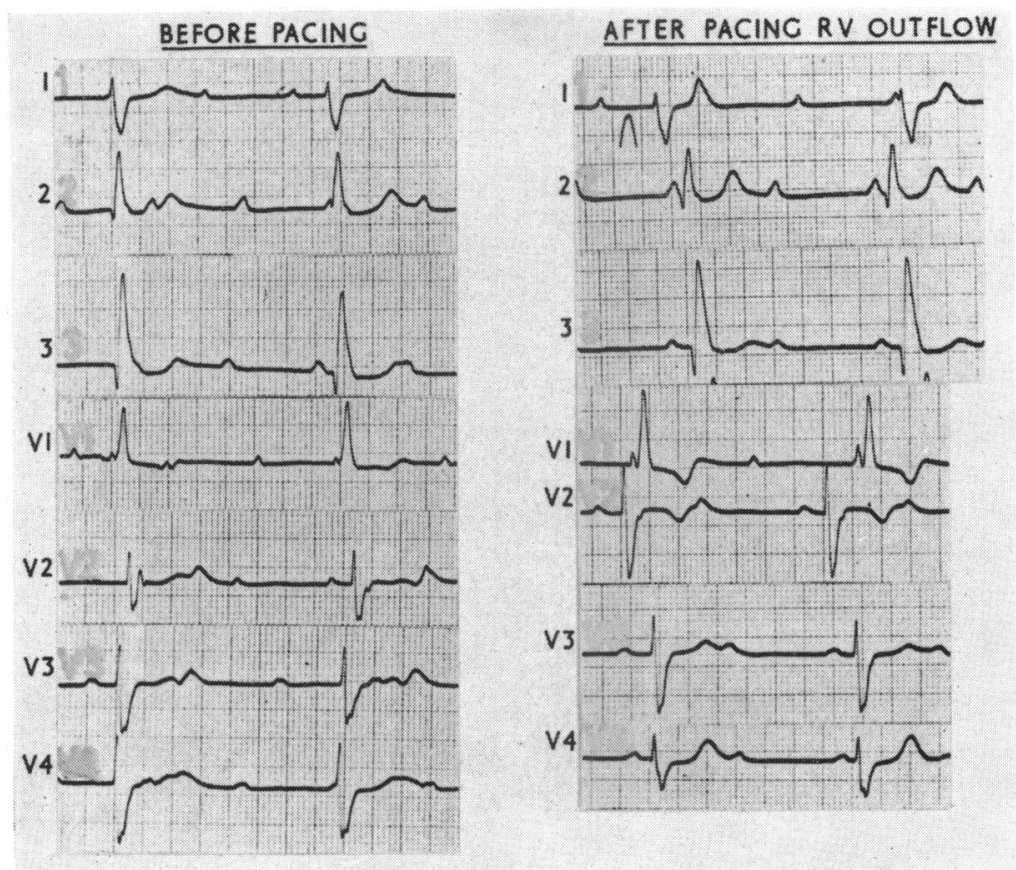

FIG. 3.-Electrocardiograms of a patient with complete heart block pre- and post-pacing. The endocardial electrode was in the outflow tract of the right ventricle and after pacing $T$ wave changes are confined to V1 and V2.

heart by means of an endocardial electrode in the right ventricular apex (26) or an epicardial electrode on the apex of the left ventricle (1): conspicuous $T$ wave inversion and ST depression occurred in leads II, III, aVF, and V3-V5 (Fig. 1 and 2). In 2 patients an endocardial electrode was in the outflow tract of the right ventricle in contact with the interventricular septum, and the changes occurred mainly in leads V1-V2 (Fig. 3, Table I, Cases 5 and 6), but when these 2 patients were paced with an endocardial electrode placed in the apical region of the right ventricle, the changes were in leads II, III, aVF, and V3-V5. The relation between the pre-paced and post-paced QRS and T axis in the frontal and horizontal planes was studied. QRS axis remained unchanged, but the mean $T$ axis was usually directed superiorly, posteriorly, and to the right when the stimulating electrode was near the apical region of the heart; posteriorly and to the left when the electrode was near the septum. The relation between $T$ wave inversion and bundlebranch block, mean frontal plane QRS axis, ventricular rate, and corrected Q-T interval is shown in Table I (patients with established complete heart block) and Table II (patients with supraventricular rhythm). The $T$ wave changes after pacing were not related to the site of origin of the idioventricular or supraventricular rhythm, with the exception of 2 patients with left bundle-branch block, in sinus rhythm, in whom no changes were observed (Fig. 4, Table II, Cases 26 and 28). All other patients, however, with left bundle-branch block in idioventricular rhythm, showed conspicuous $\mathrm{T}$ wave inversion (Fig. 5, Table I, Cases 7, 10, 17, 19). T and ST wave changes were never seen in paced beats, though an unpaced beat in the same lead showed conspicuous $T$ wave changes (Fig. 6 ), showing that the changes were masked by the abnormal spread of ventricular depolarization during pacing. No consistent changes were observed in the corrected Q-T interval after pacing; it was increased in 13, decreased in 15 , unchanged in 3 , and bore no relation to the magnitude of $T$ wave inversion.

The degree of $T$ and ST change was related to the duration of pacing, and increased in the 5 patients who were specially studied for this point, to a maximum at 12-14 days (Fig. 7). The depth of $T$ wave inversion was also related to the amount of power used for ventricular pacing, and in 6 patients studied it was observed that in individual 
TABLE I

ANALYSIS OF ELECTROCARDIOGRAMS BEFORE AND AFTER PACING IN PATIENTS WITH ESTABLISHED COMPLETE HEART BLOCK

\begin{tabular}{|c|c|c|c|c|c|c|c|c|}
\hline $\begin{array}{c}\text { Case No. } \\
1 \\
2\end{array}$ & $\frac{A \text { and } B}{A}$ & $\begin{array}{c}\begin{array}{c}\text { Bundle- } \\
\text { branch } \\
\text { block }\end{array} \\
\text { Right }\end{array}$ & Frontal plane axis & $\begin{array}{c}\begin{array}{c}\text { Ventricular } \\
\text { rate }\end{array} \\
30\end{array}$ & $\begin{array}{c}\text { Corrected } \\
\text { Q-T } \\
\text { interval } \\
(\text { sec.) }\end{array}$ & \multicolumn{2}{|c|}{$\begin{array}{c}\text { Polarity and magnitude } \\
\text { of } \mathrm{T} \text { waves in leads II } \\
\text { and V4 }\end{array}$} & $\begin{array}{c}\text { Duration of } \\
\text { pacing }\end{array}$ \\
\hline $\begin{array}{l}1 \\
2 \\
3 \\
4 \\
5 \star \\
6 \star \\
7 \\
8 \\
9 \\
10 \\
11 \\
12 \\
13 \\
14 \dagger \\
15 \\
16 \\
17 \\
18 \\
19\end{array}$ & $\begin{array}{l}\mathbf{A} \\
\mathbf{B} \\
\mathbf{A} \\
\mathbf{B} \\
\mathbf{A} \\
\mathbf{B} \\
\mathbf{A} \\
\mathbf{B} \\
\mathbf{A} \\
\mathbf{B} \\
\mathbf{A} \\
\mathbf{B} \\
\mathbf{A} \\
\mathbf{B} \\
\mathbf{A} \\
\mathbf{B} \\
\mathbf{A} \\
\mathbf{B} \\
\mathbf{A} \\
\mathbf{B} \\
\mathbf{A} \\
\mathbf{B} \\
\mathbf{A} \\
\mathbf{B} \\
\mathbf{A} \\
\mathbf{B} \\
\mathbf{A} \\
\mathbf{B} \\
\mathbf{A} \\
\mathbf{B} \\
\mathbf{A} \\
\mathbf{B} \\
\mathbf{A} \\
\mathbf{B} \\
\mathbf{A} \\
\mathbf{B} \\
\mathbf{A} \\
\mathbf{B}\end{array}$ & $\begin{array}{l}\text { Right } \\
\text { Right } \\
\text { Nil } \\
\text { Nil } \\
\text { Right } \\
\text { Right } \\
\text { Right } \\
\text { Right } \\
\text { Right } \\
\text { Right } \\
\text { Right } \\
\text { Right } \\
\text { Left } \\
\text { Left } \\
\text { Right } \\
\text { Right } \\
\text { Right } \\
\text { Right } \\
\text { Left } \\
\text { Left } \\
\text { Right } \\
\text { Right } \\
\text { Right } \\
\text { Right } \\
\text { Right } \\
\text { Right } \\
\text { Right } \\
\text { Right } \\
\text { Right } \\
\text { Right } \\
\text { Right } \\
\text { Right } \\
\text { Left } \\
\text { Left } \\
\text { Right } \\
\text { Right } \\
\text { Left } \\
\text { Left }\end{array}$ & 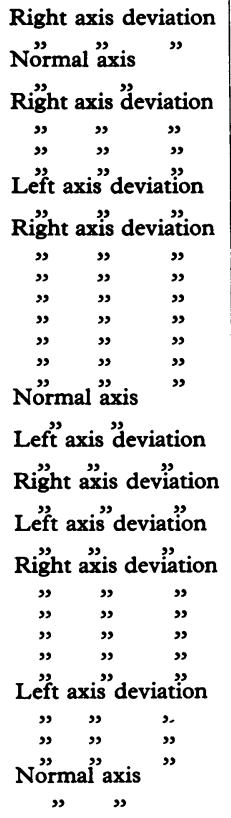 & $\begin{array}{l}38 \\
38 \\
33 \\
41 \\
35 \\
37 \\
32 \\
27 \\
40 \\
40 \\
40 \\
42 \\
39 \\
42 \\
35 \\
28 \\
32 \\
43 \\
58 \\
40 \\
49 \\
45 \\
49 \\
33 \\
39 \\
31 \\
25 \\
36 \\
35 \\
35 \\
44 \\
36 \\
40 \\
52 \\
32 \\
39 \\
39 \\
54\end{array}$ & $\begin{array}{l}0.49 \\
0.47 \\
0.37 \\
0.42 \\
0.43 \\
0.42 \\
0.59 \\
0.40 \\
0.47 \\
0.48 \\
0.49 \\
0.40 \\
0.43 \\
0.45 \\
0.58 \\
0.37 \\
0.44 \\
0.37 \\
0.42 \\
0.49 \\
0.41 \\
0.39 \\
0.41 \\
0.40 \\
0.45 \\
0.49 \\
0.37 \\
0.44 \\
0 \cdot 40 \\
0.50 \\
0.46 \\
0.41 \\
0.47 \\
0.56 \\
0.42 \\
0.45 \\
0.40 \\
0.50\end{array}$ & $\begin{array}{c}+7 \cdot 5 \\
-26 \\
+24 \\
0 \\
+5 \\
-10 \\
+6 \\
-40 \\
+21 \\
+12 \\
+12 \\
+12 \\
-10 \cdot 5 \\
-56 \\
+3 \\
-17 \cdot 5 \\
+7 \cdot 5 \\
-10 \\
+2 \cdot 5 \\
-44 \\
+12 \\
-1 \\
+14 \\
-1 \\
+12 \\
-29 \\
-22.5 \\
-9 \\
-3.5 \\
-40 \\
+5 \\
-44 \\
+29 \\
-40 \\
+13.5 \\
-16 \\
-3.5 \\
-22.5\end{array}$ & $\begin{array}{c}+21 \\
-70 \\
+38 \cdot 5 \\
+12 \cdot 5 \\
+9 \\
-12 \\
+5 \\
-72 \\
+7 \cdot 5 \\
+13 \cdot 5 \\
+5 \\
+12 \\
-96 \\
-29 \\
+49 \\
-32 \\
+5 \\
-27 \\
+6 \\
-70 \\
+39 \\
-5 \\
+7 \cdot 5 \\
-12 \\
+7 \\
-126 \\
-15 \\
-28 \\
-3.5 \\
-32 \\
+9 \\
-56 \\
+28 \\
-40 \\
+12 \\
0 \\
+2 \cdot 5 \\
-9\end{array}$ & $\begin{array}{l}1 \mathrm{dy} . \\
1 \mathrm{dy} . \\
1 \mathrm{dy} . \\
3 \mathrm{dy} . \\
3 \mathrm{dy} . \\
1 \mathrm{dy} . \\
8 \mathrm{dy} . \\
4 \mathrm{yr} . \\
4 \mathrm{yr} . \\
3 \mathrm{dy} . \\
3 \mathrm{dy} . \\
1 \mathrm{dy} . \\
43 \mathrm{yr} . \\
1 \mathrm{yr} . \\
2 \mathrm{dy} . \\
4 \mathrm{dy} . \\
14 \mathrm{dy} . \\
15 \mathrm{~min} . \\
2 \mathrm{dy} .\end{array}$ \\
\hline
\end{tabular}

Magnitude of $T$ wave has been expressed in Ashman units (see text). A = Pre-paced (control) electrocardiogram; $B=$ Unpaced electrocardiogram after pacing.

^ Stimulating electrode in right ventricular outflow tract.

† Epicardial electrode near left ventricular apex.

TABLE II

ANALYSIS OF ELECTROCARDIOGRAMS BEFORE AND AFTER PACING IN PATIENTS WITH SINUS RHYTHM

\begin{tabular}{|c|c|c|c|c|c|c|c|c|c|}
\hline Case No. & $A$ and $B$ & $\begin{array}{c}\text { Bundle- } \\
\text { branch } \\
\text { block }\end{array}$ & \multicolumn{2}{|c|}{ Frontal plane axis } & $\begin{array}{l}\text { Ventricular } \\
\text { rate }\end{array}$ & $\begin{array}{l}\text { Corrected } \\
\text { Q-T } \\
\text { interval } \\
\text { (sec.) }\end{array}$ & \multicolumn{2}{|c|}{$\begin{array}{c}\text { Polarity and magnitude } \\
\text { of } \mathrm{T} \text { waves in leads II } \\
\text { and V4 }\end{array}$} & $\begin{array}{c}\text { Duration of } \\
\text { pacing }\end{array}$ \\
\hline $\begin{array}{l}20 \\
21 \\
22 \\
23 \star \\
24 \\
25 \\
26 \\
27 \\
28 \\
29 \\
30 \\
31\end{array}$ & $\begin{array}{l}\mathbf{A} \\
\mathbf{B} \\
\mathbf{A} \\
\mathbf{B} \\
\mathbf{A} \\
\mathbf{B} \\
\mathbf{A} \\
\mathbf{B} \\
\mathbf{A} \\
\mathbf{B} \\
\mathbf{A} \\
\mathbf{B} \\
\mathbf{A} \\
\mathbf{B} \\
\mathbf{A} \\
\mathbf{B} \\
\mathbf{A} \\
\mathbf{B} \\
\mathbf{A} \\
\mathbf{B} \\
\mathbf{A} \\
\mathbf{B} \\
\mathbf{A} \\
\mathbf{B}\end{array}$ & $\begin{array}{l}\text { Right } \\
\text { Right } \\
\text { Nil } \\
\text { Nil } \\
\text { Nil } \\
\text { Nii } \\
\text { Nil } \\
\text { Nil } \\
\text { Right } \\
\text { Right } \\
\text { Right } \\
\text { Right } \\
\text { Left } \\
\text { Left } \\
\text { Nil } \\
\text { Nil } \\
\text { Left } \\
\text { Left } \\
\text { Nil } \\
\text { Nil } \\
\text { Nil } \\
\text { Nil } \\
\text { Nil } \\
\text { Nil }\end{array}$ & 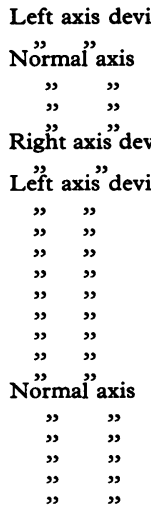 & $\begin{array}{l}\text { iation } \\
\text { " } \\
\text { viation } \\
\text { iation } \\
\text { ” } \\
\text { ” } \\
\text { ” } \\
\text { ” } \\
\text { ” }\end{array}$ & $\begin{array}{l}62 \\
68 \\
71 \\
54 \\
60 \\
75 \\
45 \\
61 \\
79 \\
79 \\
71 \\
75 \\
83 \\
80 \\
89 \\
93 \\
83 \\
75 \\
68 \\
72 \\
75 \\
89 \\
71 \\
73\end{array}$ & 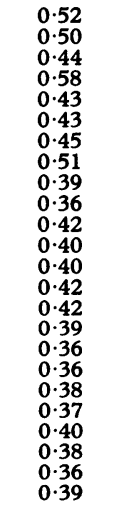 & $\begin{array}{l}+2 \\
-4 \\
+2 \cdot 5 \\
-7 \\
-7 \cdot 5 \\
-12 \\
+9 \\
-18 \\
+12 \\
-6 \\
+2 \\
-2 \\
-6 \\
-6 \\
-7 \cdot 5 \\
-12 \\
+9 \\
+7 \cdot 5 \\
+6 \\
-2 \\
+7 \cdot 5 \\
0 \\
+5 \\
-7\end{array}$ & $\begin{array}{l}-1 \\
-18 \\
+7 \cdot 5 \\
-12 \\
+15 \\
-18 \\
+2 \\
-28 \\
+2 \\
-2 \\
+2 \\
-12 \\
+30 \\
+30 \\
-1 \\
-4 \\
+15 \\
+13 \\
+6 \cdot 5 \\
-14 \\
+18 \\
-44 \\
+12 \\
-8\end{array}$ & $\begin{array}{c}1 \mathrm{dy} . \\
1 \mathrm{dy} . \\
26 \mathrm{~min} . \\
1 \mathrm{dy} . \\
1 \mathrm{dy} . \\
3 \mathrm{dy} . \\
7 \mathrm{dy} . \\
10 \mathrm{~min} . \\
2 \mathrm{dy} . \\
10 \mathrm{~min} . \\
10 \mathrm{~min} . \\
10 \mathrm{~min} .\end{array}$ \\
\hline
\end{tabular}

Magnitude of $T$ wave has been expressed in Ashman units (see text). A = Pre-paced (control) electrocardiogram; $B=$ Unpaced electrocardiogram after pacing. 


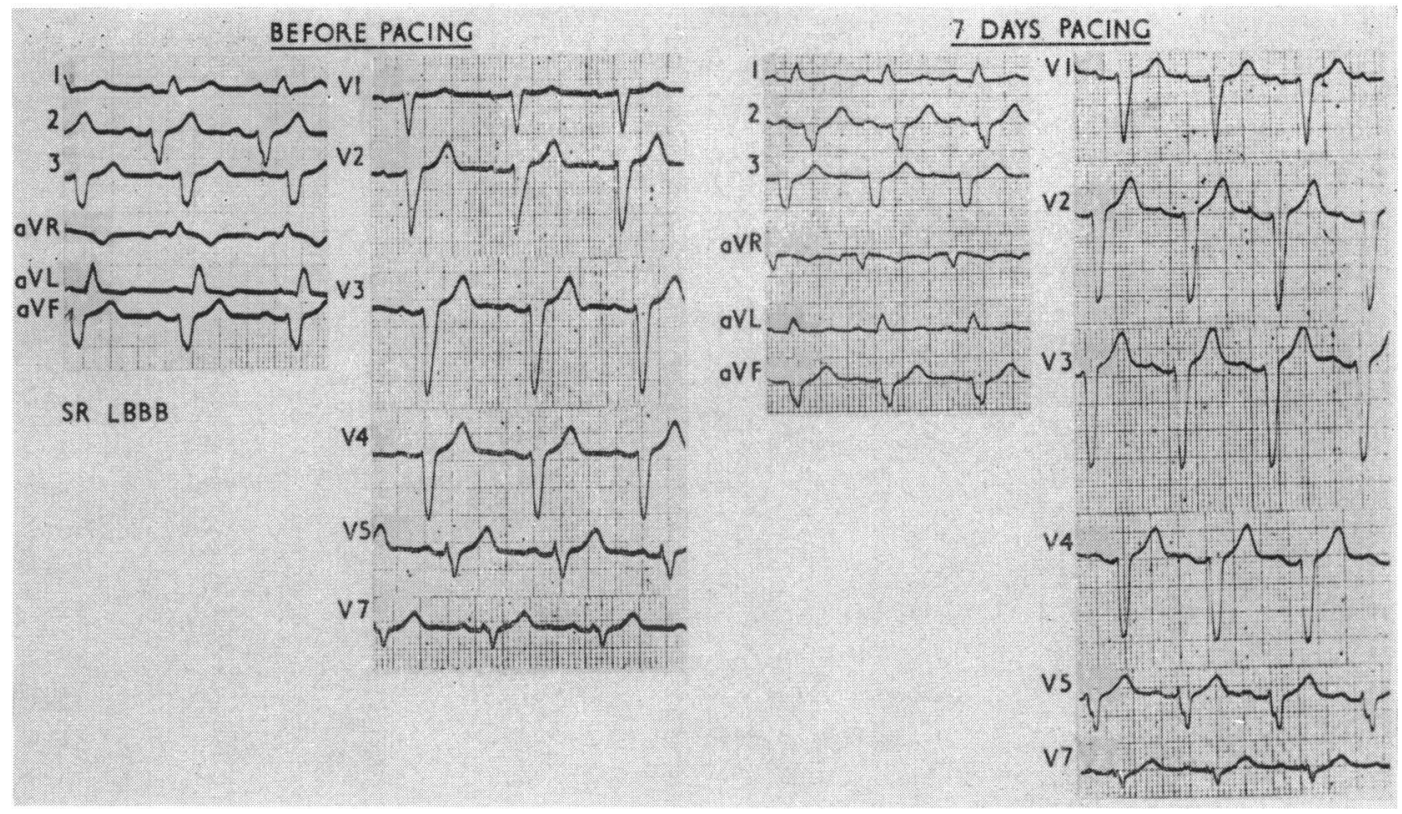

FIG. 4.-After 7 days of endocardial pacing no $T$ wave changes occurred in the unpaced electrocardiograms in the patients with sinus rhythm and left bundle-branch block.

patients, if more power was used for a given length of time, keeping the pacing rate constant, the more conspicuous was the $T$ wave inversion. The influence of ventricular rate on the magnitude of postpacing $T$ wave inversion was studied in 3 patients with chronic heart block by increasing the ventricular rate with an isoprenaline infusion after $T$ wave inversion had been produced by pacing for 24 hours. With higher ventricular rates the magnitude of $T$ inversion was slightly reduced.

The duration of $T$ and ST changes after pacing depended on the duration of pacing. For example, 10 minutes of endocardial pacing caused changes that persisted for only 15 minutes while 2 years of pacing caused changes that had not completely regressed after 18 months (Fig. 8).

The minimum time for the appearance of the $T$ and ST changes due to pacing was studied in 6 patients. Changes were observed within as short a period as 10 minutes of pacing with high voltage at fast rates $(5$ volts at $2 \mathrm{~m}$. sec. duration at a rate of $120 / \mathrm{min}$.) (Fig. 9).

The effect of positioning the electrode in the ventricle without pacing was studied in 12 patients. The transvenous electrode was left wedged at the apex of the right ventricle and no $T$ and ST changes appeared. Pacing was then started and after 15 to 20 minutes the usual changes were observed: they regressed with cessation of pacing in spite of the presence of the electrode in situ.

In 4 patients the effect of a glucose, insulin, and potassium infusion was studied. In 2 in whom pacing rate, power, and duration were held constant, the polarizing solution appeared to delay the appearance of $T$ wave inversion. In one of them infusion was continued for 120 minutes and $T$ and ST changes persisted for longer than expected from pacing alone and also took a longer time to reappear when pacing was reinstituted. In the other 2 patients the infusion of glucose, insulin, and potassium had no effect. The extracellular potassium was increased by giving $56 \mathrm{mEq}$ oral potassium in the form of slow $\mathrm{K}$ in another 2 patients without affecting the post-pacing $T$ wave inversion in one, and the $T$ inversion became wider and deeper in the other, but there was also slowing of the ventricular rate (Fig. 5).

In 3 patients in sinus rhythm, a period of pacing by means of atrial stimulation was not followed by $T$ and ST abnormalities, because the ventricle had been depolarized through natural pathways.

To study whether it was the artificial stimulation alone or the resulting depolarization which caused the post-pacing $T$ and ST changes, the following investigation was performed in 2 patients in sinus rhythm with normal conducting systems at the time 


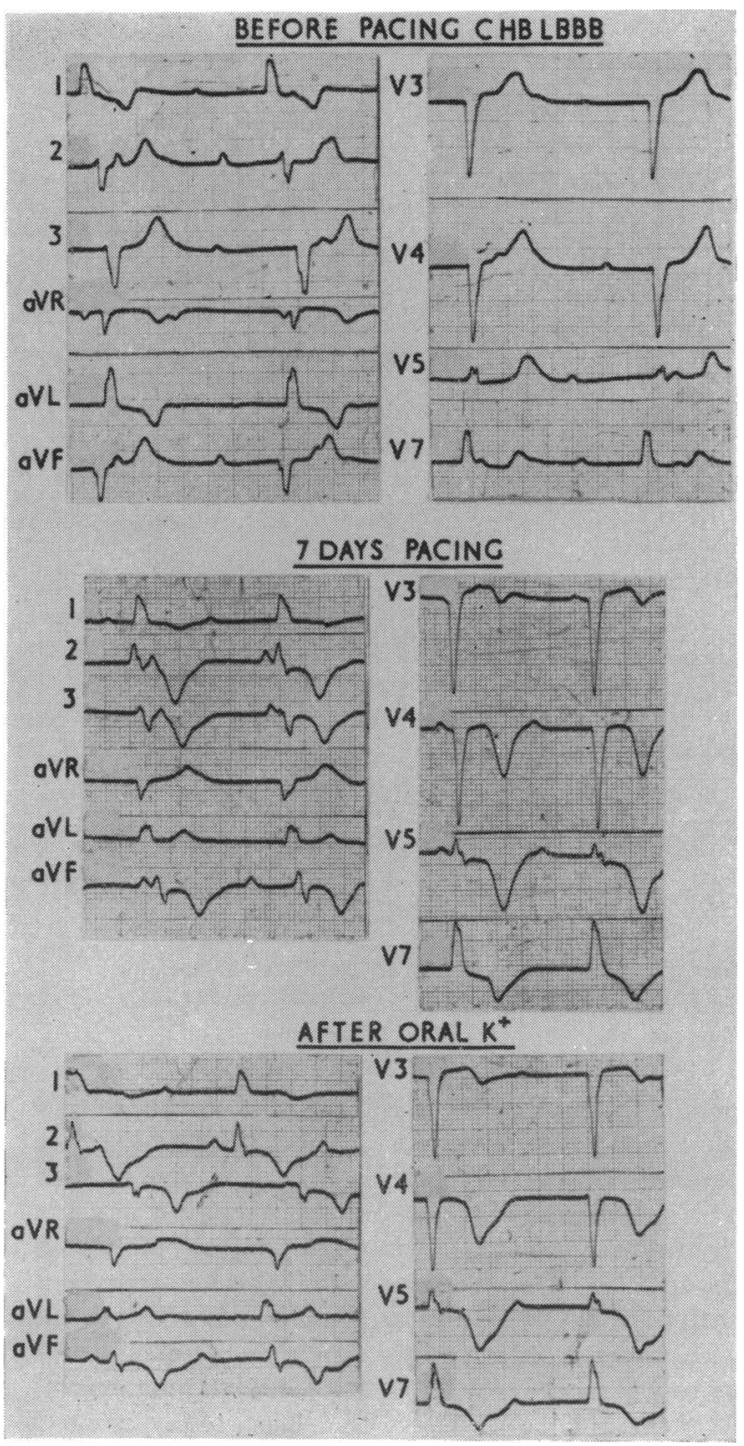

Fig. 5.-After 7 days of endocardial pacing conspicuous $T$ wave inversion occurred in the unpaced electrocardiogram in II, III, aVF, and V3-V7 in a patient with a complete heart block and left bundle-branch block pattern. Also shown is the effect of oral potassium on the $T$ wave changes which, in this patient, become wider and deeper.

of a catheter investigation for coronary disease. The heart rate was increased by pacing the right atrium with a transvenous electrode without producing $T$ wave changes. A second transvenous electrode was placed near the apex of the right ventricle and, while atrial pacing continued, a stimulus was delivered ( 5 volts at $2 \mathrm{~m}$. sec.) into the right ventricle. The time interval between the atrial

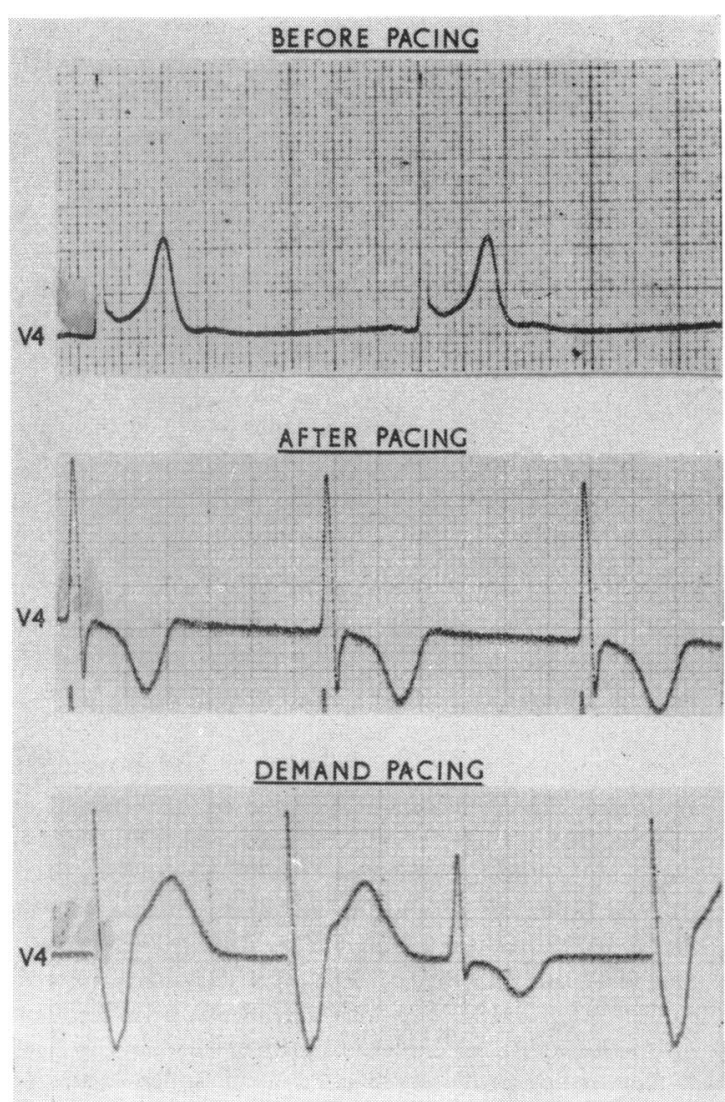

FIG. 6.-T wave inversion produced in V4 by a period of continuous endocardial pacing. These $T$ wave changes are masked by pacemaker depolarization of the ventricle, and this is shown in the first, second, and fourth complex of the strip recorded during demand pacing.

stimulus and the ventricular stimulus was so adjusted that the ventricular stimulus fell on the QRS complex (i.e. during the absolute refractory period) produced by the atrial stimulus (Fig. 10). The ventricle received an artificial stimulus without depolarization for 30 minutes and no changes were observed in the $T$ wave and ST segments of the unpaced electrocardiogram. The procedure was 


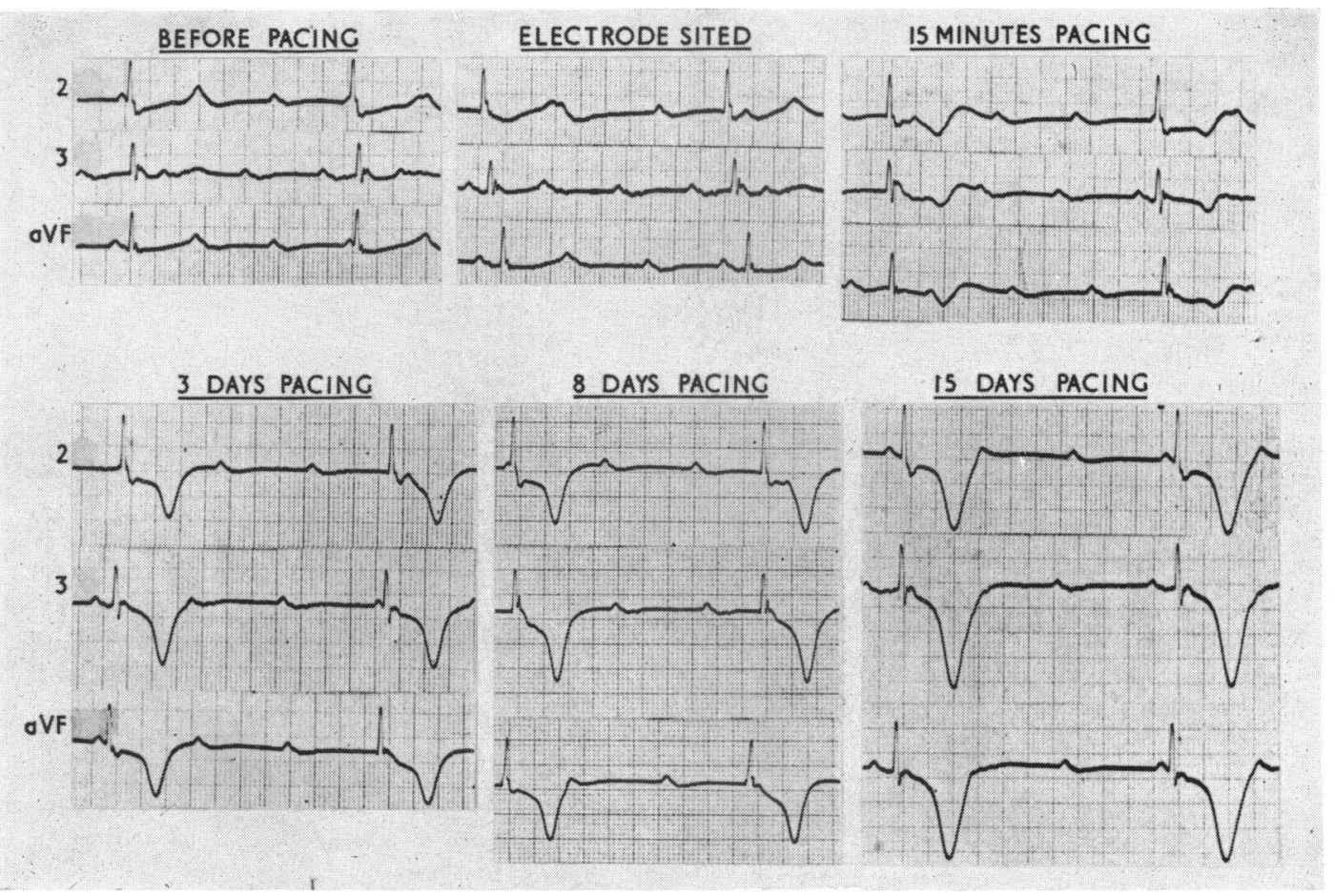

FIG. 7.-Series of unpaced electrocardiograms obtained from the same patient during 15 days of endocardial pacing. The T wave inversion progressively increased in II, III, and aVF, reaching a maximum on day 15.

then repeated using identical rate and power, but with the ventricular stimulus just preceding the QRS complex (non-refractory period) causing capture and depolarization. After a period of 10 minutes, pacing was stopped and $\mathrm{T}$ and ST changes were found (Fig. 10). Thus, the post-pacing $T$ and ST changes were the result of continuous abnormal depolarization rather than an injury pattern from the artificial electrical stimulus.

Serum enzymes were estimated before and after pacing in 7 patients and there were no significant changes, indicating that myocardial necrosis was unlikely to be the cause of the T and ST abnormality.

\section{Discussion}

The $T$ inversion and ST depression found after ventricular pacing is a primary abnormality of ventricular repolarization and is not related to changes in the QRS complex, which remained the same before and after pacing. The $T$ and ST changes were absent in only 2 of the 31 paced patients who were examined for this phenomenon. In both exceptions the rhythm before and after pacing was sinus with left bundle-branch block, and it is possible that the left bundle-branch block obscured the changes. Admittedly, there were 4 other patients with a left bundle-branch block pattern who showed the changes, but they were not in sinus rhythm. Furthermore, in one patient who showed the usual $\mathrm{T}$ and ST changes while in sinus rhythm with normal QRS complex, the changes disappeared with transient left bundle-branch block which could be repeatedly produced by the Valsalva manoeuvre. $T$ and ST changes were, of course, also obscured during the period of ventricular pacing with abnormal spread of depolarization.

At first we attributed transient $T$ inversion in patients admitted to the pacing unit to recent Adams-Stokes attacks (Ippolito, Blier, and Fox, 1954; Szilagyi and Solomon, 1959; Jacobson and Schrire, 1966), but recent attacks were excluded in the 31 patients chosen for the study. Underlying small or large coronary artery disease with a recent ischaemic episode was suggested (Wood and Wolferth, 1934; Silverman and Goodman, 1949; Garcia-Palmieri et al., 1956; Pruitt, Klakeg, and Chapin, 1955; Fisch, 1961), but the $\mathrm{T}$ inversion was too constantly present in a group of patients expected to have normal vessels and bilateral 


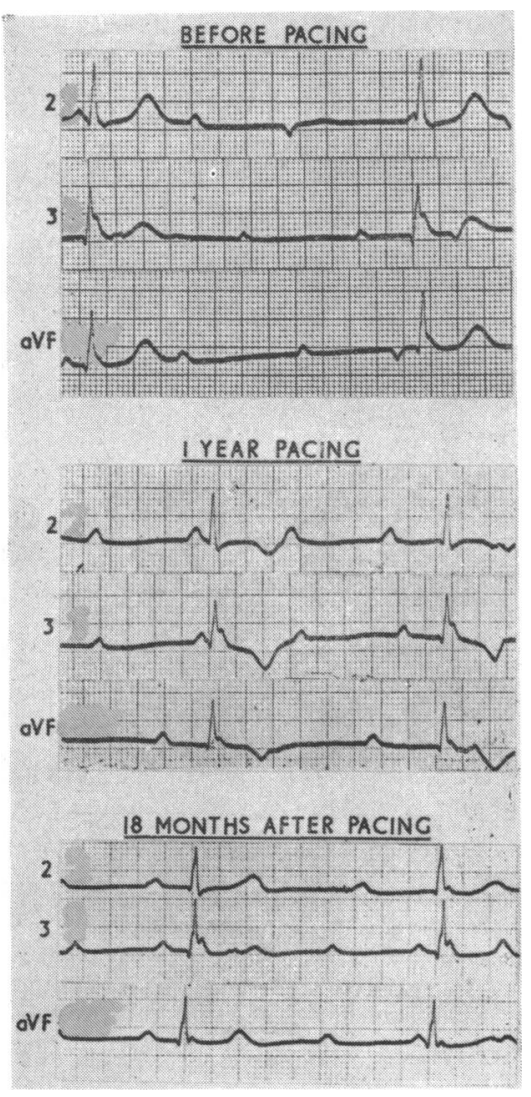

Fig. 8.-Series of unpaced electrocardiograms to show the persistence of $T$ and $S T$ changes produced by ventricular pacing. The pre-paced electrocardiogram shows upright $T$ waves in II, III, and aVF. After one year of continuous pacing, the unpaced electrocardiogram shows $T$ inversion in II, III, and aVF, and these changes took 18 months to regress.

bundle-branch fibrosis as the cause of their heart block (Harris et al., 1969). Myocardial injury was made unlikely by the invariable absence of QRS changes, the reversible nature of the $T$ and ST changes, and the absence of enzyme changes. Slow heart rates may be associated with transient $T$ inversion (Scherf, 1944), but there was no relation in this series. Furthermore, there was no difference in the $T$ inversion after slow or fast pacing, and speeding with isoprenaline did not reverse the changes.

The presence of the electrode alone in the ventricle did not produce $T$ and ST changes. Neither atrial pacing nor the timed discharge of the electrical stimulus into the ventricle in the refractory period without causing depolarization produced any change. Finally, it was shown that artificial de-

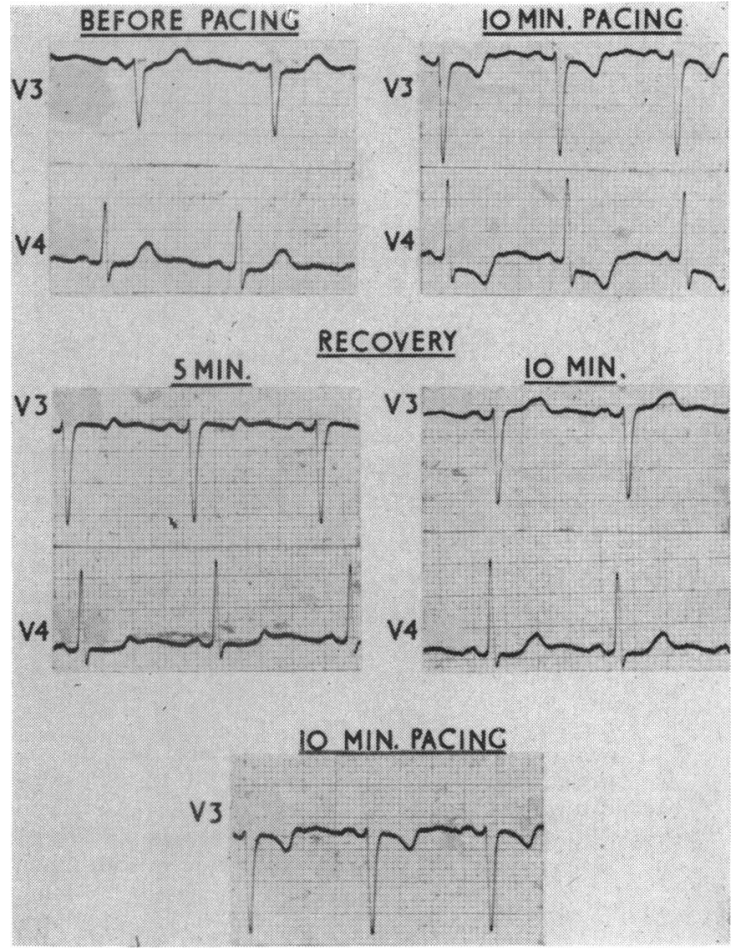

FIG. 9.-Series of unpaced electrocardiograms obtained from the same patient pre-pacing and after short intervals of endocardial pacing. Immediately after 10 minutes of endocardial pacing $\mathrm{T}$ inversion occurred in V3-V4, which fully regressed within 10 minutes. A further 10 minutes of pacing produced $\mathrm{T}$ inversion in $\mathrm{V} 3$.

polarization of the ventricle was required for the post-pacing $T$ and $S T$ changes to ensue.

The $T$ wave of the electrocardiogram, unlike the QRS complex, is known to be easily influenced by numerous factors (Levine, 1953). Transient $T$ inversion may follow cerebrovascular accidents and no abnormality is found on histological examination of the myocardium (Burch, Meyers, and Abildskov, 1954; Levine, 1953; Cropp and Manning, 1960; Fentz and Gormsen, 1962). So-called functional $T$ inversion may be abolished by potassium (Wasserburger and Corliss, 1962), but persists with organic changes such as infarction (Sharpey-Schafer, 1943), and it was interesting that the $T$ inversion persisted and even became deeper in the one patient given potassium (Fig. 5). There is nothing else to 


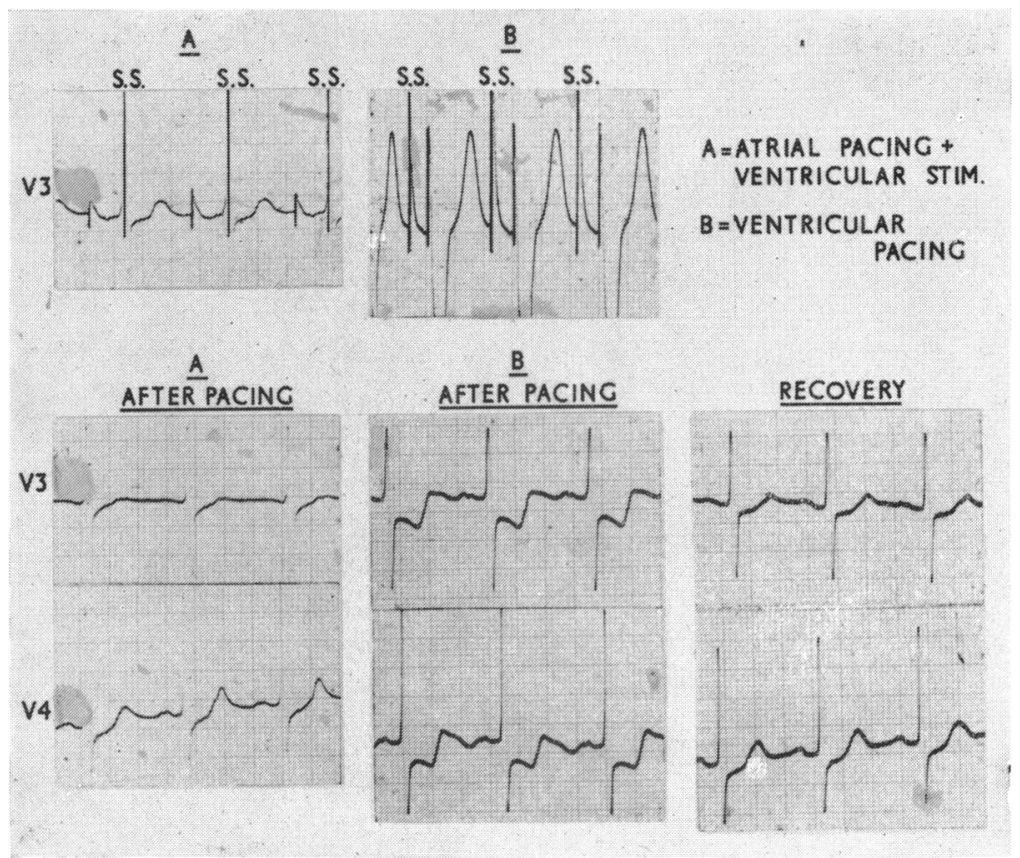

FIG. 10.-Electrocardiograms obtained from the same patient with a normal conducting system during and immediately after a period of atrial pacing with a ventricular stimulus falling in the absolute refractory period of the atrial paced beat for 30 minutes. (A). Immediately after pacing, no $T$ wave changes were seen in V3-V4. (B). When the ventricular stimulus was delivered earlier, thus causing capture and depolarization of the ventricle, $\mathrm{T}$ and ST changes were seen immediately after pacing was stopped and fully recovered 10 minutes later.

suggest, however, that the changes that we have described after depolarization from an abnormal site are of any clinical importance, except that they may be misinterpreted as evidence of progressive coronary or myocardial disease. They may be akin to the effect of ventricular ectopic beats or paroxysmal tachycardia producing changes in the $T$ wave of succeeding sinus beats in normal subjects.

\section{SUMMARY}

The effect of a period of fixed rate artificial pacing of the heart on the unpaced electrocardiogram has been studied in 31 patients, of whom 26 had chronic heart block treated by long-term fixed-rate ventricular pacing, 3 had transient heart block after acute myocardial infarction, and 2 with normal conducting tissue were being investigated for coronary artery disease. The methods of pacing were transvenous with right ventricular endocardial electrodes in $\mathbf{3 0}$ patients and left ventricular epicardial in the other.

Massive $\mathrm{T}$ wave inversion and ST depression occurred in subsequent unpaced electrocardiograms in 29 of the 31 patients. The magnitude of $\mathrm{T}$ inversion was related to the amount of electrical power used for ventricular pacing. Though these changes always disappeared spontaneously after pacing was stopped, the time required for complete regression was sometimes 1 or 2 years and was found to be related to the duration of pacing.

The $T$ wave inversion and ST depression were not caused by the presence of the electrode alone nor by the artificial stimulus used for ventricular pacing, but by ventricular depolarization from an abnormal site.

We wish to thank Miss S. Grainger, Miss A. Edwards, Miss L. Morris, and Mrs. W. French for their technical assistance in carrying out this study, and Miss P. Myers for secretarial help.

\section{REFERENCES}

Ashman, R., and Byer, E. (1943). The normal human ventricular gradient. Amer. Heart f., 25, 16.

Burch, G. E., Meyers, R., and Abildskov, J. A. (1954). A new electrocardiographic pattern observed in cerebrovascular accidents. Circulation, 9, 719.

Cropp, G. J., and Manning, G. W. (1960). Electrocardiographic changes simulating myocardial ischemia and 
infarction associated with spontaneous intracranial haemorrhage. Circulation, 22, 25.

Fentz, V., and Gormsen, J. (1962). Electrocardiographic patterns in patients with cerebrovascular accidents. Circulation, 25, 22.

Fisch, C. (1961). Giant negative T wave. F. Indiana med. Ass., 54, 1664.

Garcia-Palmieri, M. R., Marchand, E. J., Diaz-Rivera, R. S., Santiago-Stevenson, D., and Rodriguez, H. F. (1956). The significance of giant negative $T$ waves in coronary artery disease. Report of five cases. Amer. Heart $\mathcal{F}$., $52,521$.

Harris, A., Davies, M., Redwood, D., Leatham, A., and Siddons, H. (1969). Aetiology of chronic heart block. A clinico-pathological correlation in 65 cases. Brit. Heart f., 31, 206.

Ippolito, T. L., Blier, J. S., and Fox, T. T. (1954). Massive T-wave inversion. Amer. Heart f., 48, 88.

Jacobson, D., and Schrire, V. (1966). Giant T wave inversion associated with Stokes-Adams syncope. $S$. Afr. med. F., 40, 641.

Levine; H. D. (1953). Non-specificity of the electrocardio- gram associated with coronary artery disease. Amer. $\mathcal{F}$. Med., 15, 344.

Pruitt, R. D., Klakeg, C. H., and Chapin, L. E. (1955). Certain clinical states and pathologic changes associated with deeply inverted $\mathrm{T}$ waves in the precordial electrocardiogram. Circulation, 11, 517.

Scherf, D. (1944). Alterations in the form of the $T$ waves with changes in heart rate. Amer. Heart f., 28, 332.

Sharpey-Schafer, E. P. (1943). Potassium effects on T wave inversion in myocardial infarction and preponderance of a ventricle. Brit. Heart F., 5, 80.

Silverman, J. J., and Goodman, R. D. (1949). Massive T wave inversion with recovery. Quart. Bull. Sea View Hosp., 11, 72.

Szilagyi, N., and Solomon, S. L. (1959). Variations in the form of the $T$ wave in a case of partial heart block. Amer. Heart f., 58, 637.

Wasserburger, R. H., and Corliss, R. J. (1962). Value of oral potassium salts in differentiation of functional and organic T wave changes. Amer. F. Cardiol., 10, 673.

Wood, F. C., and Wolferth, C. C. (1934). Huge T-waves in precordial leads in cardiac infarction. Amer. Heart f., 9, 706. 